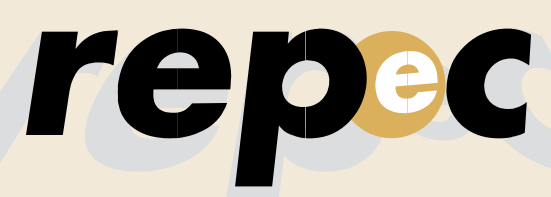

REPeC, Brasília, v. 11, n. 3, art. 4, p. 314-328, jul./set. 2017 Disponivel online em www.repec.org.br DOl: http://dx.doi.org/10.17524/repec.v11i3.1565
Revista de Educação e Pesquisa em Contabilidade Journal of Education and Research in Accounting

Periódico Trimestral, digital e gratuito publicado pela Academia Brasileira de Ciências Contábeis

ISSN 1981-8610

\title{
A Constituição do Campo Científico e a Baixa Diversidade da Pesquisa Contábil Brasileira
}

\section{Resumo}

Objetivo: Este estudo teve o objetivo de produzir uma hipótese plausível para explicar a ausência de uma linha consolidada de pesquisas interpretativas e críticas em Contabilidade no Brasil. Método: Apresento, neste estudo, uma análise da constituição do campo científico na Contabilidade brasileira, construída a partir de evidências obtidas por meio de revisão da literatura sobre a história da Contabilidade no Brasil e, subsidiariamente, de fontes documentais e de reflexões decorrentes de minha recente trajetória nesse campo, tendo como base teórica os conceitos de campo, capital, habitus e campo científico, oriundos da obra do sociólogo Pierre Bourdieu.

Resultados: Identifico a baixa autonomia do campo acadêmico em relação ao campo profissional, evidenciada pela origem dos cursos superiores em ciências contábeis a partir de esforços de lideranças da profissão e pelas constantes tentativas de ingerência das entidades profissionais sobre o ensino de Contabilidade, como causa da baixa diversidade na pesquisa contábil brasileira.

Contribuições: Em face dos constantes apelos por uma maior aproximação entre a academia e a prática contábil, os resultados deste estudo servem como um alerta para os efeitos deletérios que podem advir, se tal aproximação se der sob as atuais condições de subordinação do campo científico a interesses do campo profissional.

Palavras-chave: Campo Científico; Pesquisa Contábil Brasileira; Sociologia da Ciência.
Paulo Frederico Homero Junior

Doutorando em Controladoria e Contabilidade pela Universidade de São Paulo (USP). Contato: Av. Prof. Luciano Gualberto, 908, Sala 107, FEA3, Cidade Universitária, São Paulo/SP, CEP: 05508-010. E-mail: paulo.junior@usp.br 


\section{Introdução}

Estudos sobre a produção científica brasileira em Contabilidade têm identificado uma baixa diversidade temática, metodológica e epistemológica, com a prevalência de uma abordagem positivista a partir do início dos anos 2000 (cf. Cardoso, Mendonça Neto, Riccio, \& Sakata, 2003; Cardoso, Oyadomari \& Mendonça Neto, 2007; Leite Filho, 2008; Mendonça Neto, Riccio \& Sakata, 2009; Nascimento, Junqueira \& Martins, 2010; Theóphilo \& Iudícibus, 2005).

A ausência de uma linha consolidada de pesquisas interpretativas e críticas em Contabilidade no Brasil contrasta com os cenários de disciplinas correlatas: na Economia, tamanhas são as divergências entre as correntes ortodoxa e heterodoxa que é quase possível concebê-las como disciplinas distintas; já a área da Administração, na qual talvez não haja uma cisão tão profunda entre os distintos segmentos, é marcada por acirrados debates epistemológicos (cf. Alcadipani, 2005; Barbosa, Santos, Matos \& Almeida, 2013; Faria, 2005; Lima, 2011; Misoczky \& Amantino-de-Andrade, 2005a, 2005b; Misoczky, 2006; Rosa \& Alcadipani, 2013) e comporta uma comunidade de pesquisadores críticos cujas origens podem ser traçadas, no mínimo, à década de 1970, a partir de autores como Alberto Guerreiro Ramos, Maurício Tragtenberg e Fernando Prestes Motta (Misoczky \& Amantino-de-Andrade, 2005b).

Para compreender seu caráter monoparadigmático, investigo neste artigo como se deu a constituição do campo científico na Contabilidade brasileira, desde sua origem até os dias atuais. Em linha com análises presentes na literatura internacional, que procuram avançar na compreensão das condições sociais que levam à falta de diversidade no mainstream da pesquisa contábil (cf. Baker \& Bettner, 1997; Gendron \& Bédard, 2001; Hopwood, 2007; Humphrey \& Gendron, 2015; Jeanjean \& Ramirez, 2009; Merchant, 2010; Sikka, Willmott \& Puxty, 1995), adoto o referencial sociológico de Pierre Bourdieu para interpretar evidências obtidas a partir da literatura sobre a história da Contabilidade no Brasil e, subsidiariamente, de fontes documentais e de reflexões decorrentes de minha recente trajetória nesse campo.

A investigação segue uma lógica abdutiva, composta por três momentos interconexos: a problematização de fenômenos empíricos, a explicação retrodutiva desses fenômenos e a persuasão das audiências às quais o trabalho se destina (Glynos \& Howarth, 2007). Desta forma, partindo do problema da baixa diversidade paradigmática na pesquisa contábil brasileira, busco produzir uma hipótese plausível para explicá-la. Não se trata, porém, tal como na lógica indutiva, de uma busca por generalizações inferidas a partir de regularidades empíricas, mas, sim, de uma tentativa de gerar explicações razoáveis para o problema investigado.

Na sequência do artigo, apresento os conceitos de campo, capital e habitus na Seção 2, conforme definidos por Bourdieu, bem como as considerações do referido autor sobre as especificidades do campo científico. Na Seção 3, analiso, sob este referencial, a constituição e o desenvolvimento dos campos acadêmico e científico da Contabilidade brasileira. Proponho ainda comparações com a área de administração que, em virtude da afinidade temática e origem comum com a Contabilidade nas escolas de comércio, permitem reforçar os argumentos expostos. Ao final do artigo, sumarizo na Seção 4 as análises efetuadas ao longo do texto e indico temas que podem ser aprofundados por pesquisas futuras. 


\section{Campo, Capital e Habitus}

Ao longo de sua obra, o sociólogo francês Pierre Bourdieu se vale extensivamente do conceito de campo. Para ele:

Em termos analíticos, um campo pode ser descrito como uma rede, ou uma configuração, de relações objetivas entre posições. Essas posições são definidas objetivamente, em sua existência e nas determinações que impõem sobre seus ocupantes, agentes ou instituições, pela sua situação (situs) presente e potencial na estrutura da distribuição de espécies de poder (ou capital) cuja posse comanda acesso aos ganhos específicos em disputa no campo, bem como por sua relação objetiva com outras posições (dominação, subordinação, homologia, etc.) (Bourdieu \& Wacquant, 1992, p. 97, tradução nossa).

Em cada campo há uma constante disputa entre diferentes agentes e instituições, que segue as regularidades e regras que constituem este espaço de jogo, conferindo ao campo sua historicidade. Dependendo da conjuntura, as próprias regras podem ser objeto de disputa; assim, os limites de um campo são dinâmicos e cada um deles constitui um espaço de disputa potencialmente aberto.

O acesso ao campo é garantido aos indivíduos que possuam uma configuração específica de propriedades, definidas por Bourdieu (2002) como capital. Ele sustenta que:

Dependendo do campo em que funcione, e dos custos associados às transformações mais ou menos dispendiosas que são pré-condição para sua eficácia no campo em questão, o capital pode se apresentar sob três formas fundamentais: como capital econômico, que é imediata e diretamente conversível em dinheiro e pode ser institucionalizado na forma de direitos de propriedade; como capital cultural, que é conversível, sob certas condições, em capital econômico e pode ser institucionalizado na forma de credenciais educacionais; e como capital social, construído através de obrigações sociais ("conexões"), que é conversível, sob certas condições, em capital econômico e pode ser institucionalizado na forma de títulos de nobreza. (Bourdieu, 2002, p. 282, tradução nossa).

Bourdieu (1989) define ainda o capital simbólico, "geralmente chamado prestígio, reputação, fama, etc., que é a forma percebida e reconhecida como legítima das diferentes espécies de capital” (pp. 134135), e alega que os efeitos específicos das diferentes formas de capital dependem da estrutura do campo, ou seja, da distribuição desigual de capitais, fazendo com que os conceitos de capital e campo sejam indissociáveis, pois, "para construir o campo, é preciso identificar as formas específicas de capital que nele operam, e, para construir as formas específicas de capital, é preciso conhecer a lógica específica do campo"(Bourdieu \& Wacquant, 1992, p. 108, tradução nossa).

O estudo de um campo compreende três momentos interconexos: uma análise da posição do campo em relação ao campo de poder (reconceituação bourdieusiana da noção de classe dominante (Wacquant, 2013)); um mapeamento da estrutura de relações entre as posições ocupadas pelos agentes ou instituições que competem pela forma legítima de autoridade específica no campo (Bourdieu \& Wacquant, 1992); e uma análise do habitus dos agentes, isto é, "os diferentes sistemas de disposições que eles adquiriram, internalizando um determinado tipo de condição econômica e social, e que encontra em uma trajetória definida dentro do campo sob consideração uma oportunidade mais ou menos favorável para se atualizar"(Bourdieu \& Wacquant, 1992, p. 105, tradução nossa).

Ao explicar como as regras do campo são apropriadas por agentes dotados de diferentes valências de capital, o habitus provê uma ponte teórica entre os conceitos de campo e capital. Sendo um produto da história: 
Ele assegura a presença ativa das experiências passadas que, depositadas em cada organismo sob a forma de esquemas de percepção, de pensamento e de ação, tendem, mais seguramente do que todas as regras formais e todas as normas explícitas, a garantir a conformidade das práticas e sua constância através do tempo. (Bourdieu, 1980, p. 91, tradução nossa).

Portanto, o habitus é uma maneira de teorizar as ações sociais como produtos de um senso prático que é socialmente constituído, em oposição a noções de agência racional, provendo uma explicação de como a estrutura, da qual o habitus é o produto, governa as práticas, não por meio de um determinismo mecanicista, mas pela imposição de limites e restrições aos comportamentos considerados convenientes. Assim, nas análises apresentadas na sequência do texto, ao se identificarem as práticas de indivíduos com as posições que ocupam no campo e os interesses que representam, não se está a pôr em dúvida sua autenticidade, como se tais práticas decorressem tão somente de uma razão instrumental, sujeitas a mudanças ao sabor das conveniências. Trata-se apenas de reafirmar a proposição teórica de que há uma constituição social do habitus, e de que não só as práticas sociais refletem as posições ocupadas pelos indivíduos, mas também de que os indivíduos acabam por ocupar tais posições por se adequarem às práticas que elas impõem.

\subsection{Campo científico}

Bourdieu (1976) postula que a verdade científica resulta de condições sociais de produção particulares, ou seja, da estrutura e do funcionamento do campo científico. Para ele:

O universo "puro" da ciência mais "pura" é um campo social como qualquer outro, com suas relações de força e seus monopólios, suas lutas e suas estratégias, seus interesses e seus ganhos, mas onde todas estas características se revestem de formas específicas. (p. 89, tradução nossa).

A disputa que se dá no campo científico é pelo monopólio da autoridade científica, espécie particular de capital social entendida como a capacidade de falar e agir legitimamente em matéria de ciência. E a principal característica deste campo é o fato de que os produtores tendem, tanto mais quanto maior for a autonomia do campo, a não ter outros possíveis clientes que não seus próprios concorrentes. Assim, em um campo científico altamente autônomo, um indivíduo só poderá obter reconhecimento do valor de seus produtos, na forma de reputação, prestígio, autoridade, etc., a partir do julgamento de seus pares, que, justamente por serem seus concorrentes, serão pouco propensos a conceder tais benefícios, senão após discussões e exames acurados.

Na luta pela legitimidade científica, os indivíduos em posição dominante no campo tendem a adotar estratégias de conservação, visando perpetuar a ordem científica estabelecida. Tais estratégias incluem não apenas a preservação das instituições encarregadas da produção e circulação das ideias científicas, mas também o controle sobre aquelas que reproduzem o habitus científico corrente, notadamente às instituições de ensino.

Já os postulantes a posições de domínio podem adotar estratégias de sucessão ou de subversão. Estratégias de sucessão visam assegurar ao indivíduo, ao final de uma carreira previsível, os ganhos prometidos a quem segue o ideal estabelecido de excelência científica, limitando-se a inovações circunscritas aos limites do campo e tomando parte no ciclo de troca de reconhecimento pelo qual a autoridade científica é transmitida entre gerações.

Estratégias de subversão, por sua vez, visam redefinir as regras de legitimação da dominação, de maneira que seus adotantes possam iniciar a acumular capital sem conceder uma contraparte aos dominantes, negando-lhes reconhecimento. Tais estratégias apresentam um risco maior de insucesso e demandam um maior investimento em preparo científico, além de privar quem as adota do acesso aos ganhos disponíveis no campo, ao menos no curto prazo, pois terão contra si toda a lógica do sistema. 
Assim, Bourdieu (1976) sugere existir uma conexão entre as disposições quanto à ordem científica e quanto à ordem social, havendo maior propensão à adoção de estratégias de subversão por parte de indivíduos oriundos de grupos sociais subalternos. Além disso, afirma também que os conflitos epistemológicos são sempre, inseparavelmente, conflitos políticos, por meio dos quais os ocupantes de determinada posição buscam justificá-la e desacreditar as posições opostas.

Mas a distinção entre estratégias de conservação e de subversão tende a diminuir conforme cresça a autonomia do campo científico, pois a aquisição do preparo científico necessário para promover rupturas passa a depender de um engajamento com o próprio campo. Desta maneira, aqueles com maior preparo entre os postulantes, em vez dos que possuam menor capital científico, passam a ser os mais aptos a questionar os fundamentos da ordem estabelecida, e o campo científico passa a ser palco de revoluções permanentes. A própria capacidade de ruptura se torna fonte de prestígio e, assim, a busca pela verdade prevalece sobre a afirmação da verdade dos interesses de cada indivíduo.

Bourdieu (1976) sustenta ainda que as ciências sociais enfrentam obstáculos maiores para sua autonomização do que as ciências naturais. Enquanto as ciências naturais oferecem a possibilidade de emprego econômico dos avanços tecnológicos, sendo de interesse das classes dominantes o produto desta autonomia, as ciências sociais têm por objetivo a representação legítima do mundo social, que também é objeto de disputa no âmbito político da luta de classes.

Desta forma, Bourdieu (1976) entende que as disputas científicas nas ciências sociais sempre têm implicações políticas, posto que quaisquer alterações no entendimento do mundo social também serão de interesse nas lutas políticas, fazendo da ideia de uma ciência neutra uma ficção. Por conta dessas implicações políticas, as classes dominantes buscam nas ciências sociais, um reforço ao arsenal simbólico que legitima a ordem estabelecida, procurando submetê-las a uma relação de dependência, mas de aparente independência em relação a demandas externas. Assim, em vez de campos científicos, as ciências sociais se tornam campos produtores de discursos eruditos, caracterizados por uma estratégia de falsa ruptura que se vale de jargão erudito para reafirmar o senso comum.

\section{Constituição do Campo Científico na Contabilidade Brasileira}

A chegada da corte portuguesa ao Brasil, em 1808, deu início a uma série de transformações na sociedade local, que culminaram com a Proclamação da Independência, em 1822. Datam dessa época os primeiros grandes movimentos da profissão contábil no Brasil, como a publicação das primeiras obras sobre Contabilidade, a adoção do sistema de partidas dobradas na escrituração governamental, e a criação das primeiras aulas de comércio (Peleias \& Bacci, 2004). Ao longo do século XIX, porém, o ensino comercial logrou baixa expansão. Segundo Peleias, Silva, Segreti e Chiorotto (2007), as aulas de Comércio atraíam poucos alunos, ao passo que outros cursos, como Direito, Engenharia e Medicina tinham maior apelo dentre as classes socialmente mais favorecidas de então.

Embora a Associação de Guarda-Livros da Corte tenha sido reconhecida oficialmente ainda em 1870, foi durante a República Velha que tomaram corpo os esforços para o reconhecimento e regulação da profissão. Liderados por personalidades como Carlos de Carvalho, Francisco D’Áuria, Frederico Hermann Junior, João Lyra Tavares, entre outros, em 1911, cria-se a Revista Brasileira de Contabilidade; em 1916, criam-se o Instituto Brasileiro de Contadores Fiscais e a Associação dos Contadores, em São Paulo, e o Instituto Brasileiro de Contabilidade, no Rio de Janeiro; e, em 1924, ocorre o I Congresso Brasileiro de Contabilidade (Peleias \& Bacci, 2004).

Mendonça Neto, Cardoso e Oyadomari (2012) afirmam que, "nesta época [início do século XX], a elite do grupo ocupacional já ocupava posição de destaque na sociedade brasileira" (p. 399), congregando membros com cargos no Tesouro do Estado de São Paulo, no Tesouro Nacional e no Senado da República, para o qual João Lyra Tavares foi eleito em 1914. Os autores analisam a profissionalização da Contabilidade no Brasil, recorrendo ao conceito de Professional Project, oriundo da sociologia das profissões, que identifica as seguintes etapas nesse projeto: 
- Um objetivo global estabelecido pelo grupo ocupacional, que se traduz na busca pelo monopólio do mercado dos serviços baseados em sua expertise e por status na hierarquia social;

- Objetivos secundários que incluem:

- O estabelecimento de uma jurisdição, ou seja, o direito que um grupo ocupacional detém de controlar os serviços que presta;

- Controle sobre o processo de qualificação dos aspirantes ao ingresso na profissão, que os submeta a um sistema apropriado de seleção e treinamento, estando relacionado com a monopolização do conhecimento; e,

- Construção da respeitabilidade social da profissão (Mendonça Neto et al., 2012).

Na consecução desse projeto de profissionalização, o ensino de Contabilidade ocupou papel de destaque. Segundo Agrizzi e Sian (2015), as limitadas possibilidades de educação e treinamento comercial eram motivos de insatisfação entre os integrantes das primeiras associações profissionais, e o I Congresso Brasileiro de Contabilidade teve dentre seus objetivos a persuasão das autoridades para que requeressem um maior nível de ensino aos praticantes de tarefas contábeis. Na visão dos autores:

Isso estava no topo da agenda porque o registro de informações contábeis, bem como a preparação de relatórios contábeis, ainda eram vistos como um trabalho a ser exercido por indivíduos menos qualificados. Aumentar os padrões de educação e, portanto, competência era chave para o avanço do status social e da remuneração dos ofertantes de serviços de escrituração e contabilidade (Agrizzi \& Sian, 2015, p. 64, tradução nossa).

A partir da Revolução de 1930, com o advento da Era Vargas, teve início um período que pode ser descrito como de corporativismo estatal, caracterizado por um sistema de representação de interesses organizados em categorias diferenciadas, singulares, não-competitivas e ordenadas funcionalmente, em que o Estado oferece reconhecimento e liberdade representacional às categorias, em troca da tutela sobre os processos de seleção de lideranças e articulação de demandas (Rodrigues, Schmidt, Santos, \& Fonseca, 2011). Assim, a partir de 1930, houve uma proliferação de associações de profissionais da contabilidade por diversos estados brasileiros, como Pernambuco, Mato Grosso, Minas Gerais e Rio Grande do Sul (Peleias \& Bacci, 2004).

Agrizzi e Sian (2015) consideram que o relacionamento entre Estado e sindicatos, nessa época, era altamente assimétrico: o Governo ameaçava dissolver e impunha multas aos sindicatos que não cumprissem com as normas que expedia, tornando-os apêndices do Estado e da execução de políticas públicas. Ainda assim, para grupos ocupacionais com baixo status social, como o contábil, os autores cogitam que as recompensas oferecidas, tais como os canais institucionalizados de acesso aos centros de decisão, eram vantajosas. Este arranjo de acomodação e conveniência mútua, em que o Estado patrocinava as associações corporativas em troca de apoio político à manutenção do status quo, permitiu que as lideranças de categorias com baixo prestígio social ascendessem às altas posições perante a administração pública, e que, a partir delas, advogassem em prol dos interesses de suas categorias.

Remontam ainda a este período a submissão das escolas de comércio, a partir de 1931, a um padrão curricular nacional e à autorização e fiscalização por parte do Ministério da Educação e Saúde (Agrizzi \& Sian, 2015). O mesmo diploma legal, responsável por essa reformulação do ensino comercial, conforme Decreto-Lei no 20.158 , também regulamentou a profissão de Contador, conferindo suas prerrogativas aos portadores de diplomas outorgados pelos institutos de ensino Comercial reconhecidos oficialmente, mas permitindo que profissionais com apenas experiência prática se submetessem a exames de habilitação (Mendonça Neto et al., 2012). 
Por fim, em 1946, foram criados, pelo Decreto-Lei no 9.295, o Conselho Federal de Contabilidade (CFC) e os Conselhos Regionais de Contabilidade, consolidando o projeto profissional da categoria ao lhe conferir garantia de unidade, reconhecimento de sua jurisdição, da necessidade de obtenção de registro na categoria para o exercício da profissão, e ampliando seu monopólio (Mendonça Neto et al., 2012). A profissão foi dividida em duas habilitações distintas: Contador, para os portadores de diploma universitário; e Guarda-Livros, renomeada em 1958 como Técnico em Contabilidade, destinada a portadores de diploma em cursos de nível médio (Rodrigues, Schmidt \& Santos, 2012).

Neste mesmo ano de 1946, diversas universidades brasileiras criaram cursos de Contabilidade (Rodrigues et al., 2011). O primeiro deles foi o curso superior em ciências contábeis e atuariais instalado pela Faculdade de Ciências Econômicas e Administrativas (FCEA) da Universidade de São Paulo (USP), posteriormente denominada Faculdade de Economia, Administração e Contabilidade (FEA) (Peleias et al., 2007). A criação desse curso se deu sob influência do Sindicato dos Contabilistas de São Paulo e dos professores Frederico Hermann Junior, Milton Improta, Atilio Amatuzi e Dirceu Rodrigues, membros da elite do grupo ocupacional à época (Mendonça Neto et al., 2012).

Assim, o ingresso da Contabilidade no ambiente acadêmico brasileiro se deu por conta dos esforços levados a cabo por líderes da profissão, que foram também os responsáveis por implementar tais cursos nas universidades. Desta maneira, já em sua origem os cursos de contabilidade estavam subordinados a interesses do campo profissional, não só como parte da estratégia de diferenciação e conquista de status perante a sociedade como um todo, mas também para a acumulação de capital cultural a ser mobilizado nos conflitos existentes no âmbito interno da profissão, posto que:

Nesse grupo, uma elite que recebeu uma educação formal e que ocupava uma posição privilegiada na hierarquia social convivia com um conjunto numeroso de práticos, sem uma educação formal, mas com habilidades suficientes para realizar os serviços de escrituração simples que eram demandados no final do século XIX e nas primeiras décadas do século XX. A existência, na época, de associações destinadas exclusivamente a diplomados em Escolas de Comércio é um forte indicador desta divergência. (Mendonça Neto et al., 2012, p. 403).

Ainda hoje, iniciativas visando pautar o ensino de Contabilidade ocupam grande espaço na agenda das entidades representativas da profissão. O CFC, particularmente, tem envidado diversos esforços nesse sentido ao longo dos anos:

- Em 2000, o Conselho estabeleceu o Exame de Suficiência, com a proposta de "avaliar os conhecimentos adquiridos pelos estudantes na área de Contabilidade [grifos nossos], para que, em caso de aprovação, estes recebam o registro profissional" (Passos, 2004, p. 15), tomando para si uma responsabilidade que, via de regra, compete às Instituições de Ensino Superior (IESs);

- Após a extinção do Exame em 2004, decorrente de disputas judiciais, o Conselho se mobilizou para pleitear que ele fosse previsto legalmente, o que se concretizou a partir da Lei ${ }^{\circ}$ 12.249/2010 - segundo o Presidente do CFC à época, Sr. Juarez Domingues Carneiro:

O Exame vai exigir das Instituições de Educação Superior (IES) [grifos nossos], de modo geral, uma melhor qualificação do seu corpo docente, além de despertar nos futuros profissionais a necessidade e a responsabilidade de buscar um conhecimento mais aprofundado do que aquele que se encontra hoje em muitos cursos de Ciências Contábeis [grifos nossos] (Girotto, 2010);

- Em maio e junho de 2008, o CFC promoveu cursos de Contabilidade Internacional para professores de cursos de Ciências Contábeis oriundos de todos os estados brasileiros. À época vice-presidente de Desenvolvimento Profissional do CFC, o Sr. José Martonio Alves Coelho afirmou, na abertura das duas turmas do curso que: 
Todos sabem que existe um prazo estabelecido para a harmonização das normas contábeis ao padrão internacional. Fizemos uma pesquisa e verificamos que poucas IESs do Brasil sequer possuem Contabilidade Internacional em seus conteúdos programáticos. Preocupada com isso, a presidente Maria Clara decidiu que o CFC deveria atuar para disseminar conhecimento em relação às novas práticas de contabilidade [grifos nossos] (Santos, 2008b, p. 4);

- Ainda em 2008, o CFC elaborou uma Proposta Nacional de Conteúdos para o Curso de Graduação em Ciências Contábeis, tendo:

A finalidade de ser uma contribuição do Sistema - que reúne o CFC e os 27 Conselhos Regionais de Contabilidade - à sociedade brasileira, propondo disciplinas e conteúdos que refletem as disposições atuais e que podem satisfazer as necessidades do profissional contábil na era do conhecimento [grifos nossos] (Santos, 2008a);

- De 2006 até 2015, o Conselho organizou dez edições do Encontro Nacional de Coordenadores e Professores do Curso de Ciências Contábeis. Na solenidade de abertura da décima edição do Encontro, o então vice-presidente de Desenvolvimento Profissional e Institucional do CFC, Sr. Zulmir Ivânio Breda, declarou que:

Há um crescimento rápido no número de novos cursos de Ciências Contábeis no Brasil. Por um lado é bom, já que são mais profissionais no mercado, mas, por outro, nos preocupa, pois temos que garantir a qualidade desses cursos. Gostaríamos de participar do processo de autorização dos novos cursos [grifos nossos], para podermos garantir bons profissionais no mercado (Arduini, Oliveira, \& Rodrigues, 2015, p. 17);

De modo geral, a ingerência do CFC sobre o ensino de Contabilidade tem sido bem recebida pela comunidade acadêmica nacional, e até mesmo promovida por participantes em posição de destaque nessa comunidade, sobretudo os vinculados às IES públicas, que, provavelmente, não percebem nessas iniciativas uma ameaça a sua autonomia, mas, sim, uma oportunidade para reforçar o capital simbólico de que gozam tais instituições.

Já os cursos de graduação em Administração, por sua vez, têm uma origem marcadamente distinta em relação aos de Ciências Contábeis. Nicolini (2003) aponta a origem do ensino de Administração no Brasil, também nas Escolas de Comércio, em 1902, e destaca a criação do curso superior de Administração e Finanças, em 1931, mas que diplomava seus bacharéis em Ciências Econômicas. Habilitações específicas em Administração surgiram apenas com a criação da Escola Brasileira de Administração Pública (Ebap) e da Escola de Administração de Empresas de São Paulo (EAESP), em 1952 e 1954, respectivamente, ambas vinculadas à Fundação Getúlio Vargas (FGV), tendo sido precedidas por visitas de representantes da instituição a diversos cursos de Administração Pública de universidades norte-americanas.

A partir de convênio firmado, em 1959, entre os governos brasileiro e estadunidense, envolvendo a Ebap, a EAESP, o Departamento de Administração do Setor Público (Dasp), a Universidade Federal da Bahia (UFBA) e a Universidade Federal do Rio Grande do Sul (UFRGS), bolsistas dessas instituições foram enviados a universidades norte-americanas, e uma missão de professores estadunidenses especializados em Administração Pública e de empresas foi recebida no Brasil, encarregando-se da implementação dos programas de ensino de Administração no País, caracterizando o desenvolvimento desses cursos como uma transferência de tecnologia desenvolvida nos Estados Unidos (Nicolini, 2003).

Mas foi apenas em 1965, a partir da Lei no 4.769/1965, que se regulamentou a profissão de Administrador: 13 anos, portanto, após a criação do primeiro curso de nível superior na área, e 19 anos após a regulamentação da profissão de Contador. Assim, enquanto a Contabilidade veio "de fora para dentro" das universidades, a Administração fez o caminho oposto, com a segmentação acadêmica da disciplina precedendo a diferenciação da categoria ocupacional e seu estabelecimento como profissão. 
Tal diferença de origem indica que também a relação entre o campo acadêmico e o campo profissional seja distinta entre as duas áreas. Dada a origem acadêmica do projeto profissional dos administradores, é possível supor que a busca por status social e pela construção de respeitabilidade da profissão tenha se dado, essencialmente, por meio da academia. Com isso, foi preciso que a disciplina obtivesse prestígio no âmbito acadêmico e, para tanto, se fez necessário o estabelecimento de um campo científico suficientemente autônomo, propiciando a diversidade axiológica e epistemológica que o caracteriza.

A expansão da pós-graduação stricto sensu em Administração corrobora essa linha de raciocínio. O Brasil organizou pela primeira vez esta modalidade de pós-graduação no início da década de 1970, e a área de Administração acompanhou sua expansão desde os primeiros passos: em fins dos anos sessenta e início da década seguinte, programas surgiram no Rio de Janeiro, São Paulo, Minas Gerais, Rio Grande do Sul e Paraíba (Bertero, Caldas \& Wood Jr., 1999). Em 1978, já havia 14 cursos de mestrado e 4 de doutorado na área (Castro, 1981).

Já a Contabilidade seguiu caminho diverso: neste mesmo ano de 1978, foi inaugurado o primeiro curso de doutorado, na FEA/USP, que permaneceu sendo o único desse nível no País até 2006, quando havia apenas 15 cursos de mestrado em funcionamento, dos quais 12 haviam sido criados a partir de 1998 (Peleias et al., 2007). Ao contrário da Administração, na Contabilidade a profissão já havia garantido legalmente seu monopólio quando ingressou no meio acadêmico. Assim, a principal função ligada à academia aparentemente foi a de controle da qualificação para acesso à profissão, e o acúmulo de capital cultural pelo meio acadêmico não foi uma estratégia perseguida com intensidade.

Antes do ingresso no meio acadêmico, a Contabilidade já era palco de conflitos de interesse entre profissionais com qualificação formal em escolas de comércio e aqueles com apenas experiência prática (Mendonça Neto et al., 2012). Após a regulamentação da profissão, em 1946, esse conflito permaneceu, agora contrapondo os interesses de profissionais com formação no ensino superior e os com formação de nível técnico. Assim, a lentidão do avanço da pós-graduação em contabilidade no país também pode ter sido influenciada pelas disputas simbólicas no seio da profissão, caracterizadas pela valorização da experiência prática em detrimento de qualificações acadêmicas, como ilustra a seguinte declaração do presidente do CFC em 2003, Sr. Alcedino Gomes Barbosa:

Ensinar sem vivenciar a prática equivale a aprender a nadar por correspondência (o atual ensino a distância). Aprender a técnica poderá ser fácil, mas, nadar sem afundar, é outra questão.... Os professores são multiplicadores do conhecimento, devendo ser, portanto, experimentados naquilo que estão ensinando. A aliança entre teoria e prática é, de certa forma, indissociável. O ensino teórico dissociado da prática ou vice-versa ensejará na multiplicação do "desconhecimento de algo", cujo resultado poderá ser catastrófico. (A. G. Barbosa, 2003).

Outra disputa histórica no campo da Contabilidade brasileira se deu entre os adeptos da escola italiana, que por mais de 30 anos havia dominado o treinamento profissional e influenciado a legislação pertinente, e os da escola norte-americana, adotada e difundida pela FEA/USP desde o final dos anos 1950, período de forte crescimento econômico impulsionado pela parceria comercial com os Estados Unidos e pela chegada da indústria automobilística ao país (Rodrigues et al., 2012). Deste conflito, não há que se olvidar que as posições de liderança na academia contábil brasileira sempre foram ocupadas por indivíduos de alto prestígio também no meio profissional: o que se apresentava como uma disputa de caráter teórico pode ser interpretada como expressão dos diferentes interesses de segmentos distintos no campo profissional, uns identificados com o mercado de pequenas e médias empresas locais, outros com as empresas de capital aberto e as multinacionais que chegavam ao País à época, trazendo consigo as grandes firmas internacionais de auditoria. 
Nessa disputa, a aposta na pós-graduação como forma de acúmulo de capital cultural foi uma das estratégias adotadas pelo segmento sob influência estadunidense, liderado pela FEA/USP. Mas também esse segmento mantinha vínculos estreitos com o campo profissional, com lideranças ocupando cargos em órgãos reguladores como o Banco Central do Brasil (BCB) e a Comissão de Valores Mobiliários (CVM), participando ativamente da elaboração de normas contábeis, prestando consultorias e integrando conselhos de companhias privadas (Ribeiro, 2009). E o que se espera de um regulador, de um normatizador, de um consultor e de um conselheiro é que apresente soluções, ao contrário do habitus científico, cuja característica distintiva é a capacidade de apontar problemas.

Theóphilo e Iudícibus (2005), em análise da produção científica brasileira em Contabilidade, de 1994 a 1998 e de 1999 a 2003, sustentam que "na primeira fase, são predominantes trabalhos teóricos, que adotam postura normativa e desenvolvem investigações em profundidade, voltadas a propor novas idéias e visões" (p. 170). Tais características coadunam-se com o argumento de que a falta de autonomia em relação às práticas profissionais fez da academia contábil brasileira não um campo científico, mas, sim, um campo produtor de discursos eruditos, que sempre visou reafirmar tais práticas, em vez de questioná-las. Mesmo nas disputas entre as diferentes escolas, a Contabilidade em si jamais foi objeto de crítica; se se questionavam as práticas adotadas no País, ou as sugeridas por escola concorrente, era apenas para, em seguida, sugerir práticas distintas, mas sempre articuladas em prol de interesses profissionais.

Já para o período de 1999 a 2003, Theóphilo e Iudícibus (2005) afirmam que "o tipo de trabalho mais frequente (...) é teórico-empírico, apresenta postura teórica positiva e realiza investigações em superfície, baseadas em teorias existentes e aceitas pela comunidade científica" (p. 170). Este período coincide com o início de uma expansão acelerada da pós-graduação stricto sensu em Contabilidade no Brasil, que hoje em dia, praticamente, se equipara à Administração em termos proporcionais, conforme indicam os dados da Tabela 1, bem como a uma mudança de paradigma na pesquisa contábil, com declínio de abordagens normativas e predomínio de abordagens positivas, identificada também por Cardoso et al. (2007) e Borges, Rodrigues, Silva e Santana (2011), entre outros.

Tabela 1

Indicadores das Áreas de Administração e Contabilidade

\begin{tabular}{lccc}
\multicolumn{1}{c}{ Indicador } & Administração & Contabilidade & Administração/Contabilidade \\
\hline Matrículas na graduação $^{a}$ & 921.395 & 257.516 & 3,58 \\
\hline Cursos de graduação $^{a}$ & 4.111 & 1.168 & 3,52 \\
\hline Cursos de mestrado & 72 & 22 & 3,27 \\
\hline Cursos de doutorado & 46 & 12 & 3,83 \\
\hline
\end{tabular}

Nota. Fontes: Coordenação de Aperfeiçoamento de Pessoal de Nível Superior. (n.d.). Plataforma Sucupira. Recuperado em 10 de janeiro de 2016, de https://sucupira.capes.gov.br/sucupira/ \& Instituto Nacional de Estudos e Pesquisas Educacionais Anísio Teixeira. (2015). Sinopses Estatísticas da Educação Superior: Graduação. Recuperado em 10 de janeiro de 2016, de http://portal.inep.gov.br/superior-censosuperior-sinopse

a Dados relativos a 2013. 
Em conjunto, a expansão da pós-graduação e a "virada positivista" na pesquisa contábil brasileira sugerem um processo de maior autonomização do campo científico em relação à prática profissional. Quanto à expansão da pós-graduação, porém, uma hipótese a ser considerada é a de que ela também reflita mudanças no campo profissional. Além dos conflitos de interesses entre profissionais com formação superior e os de nível técnico, que culminou com a extinção do registro de técnicos em contabilidade a partir de $1 \% / 6 / 2015$, determinada pela Lei $\mathrm{n}^{\circ} 12.249 / 2010$, pode-se conjecturar ainda que o acirramento do conflito com outras profissões tenha levado a uma maior busca pela acumulação de capitais cultural e simbólico no meio acadêmico, como estratégia para manter ou expandir o monopólio de que goza a categoria. Corrobora esse entendimento o papel desempenhado pelo CFC, que em 1994 instituiu o Programa Excelência na Contabilidade, visando intensificar a realização de cursos de pós-graduação stricto sensu em Contabilidade por meio de convênios firmados com IES recomendadas pela Coordenação de Aperfeiçoamento de Pessoal de Nível Superior (Capes), oferecendo suporte financeiro aos projetos conveniados:

$\mathrm{Na}$ origem da instalação do Programa Excelência na Contabilidade, está a constatação de que o ensino de pós-graduação no Brasil vinha experimentando excepcional crescimento, o que representa um auspicioso ganho em qualidade profissional e acadêmica, mas na área contábil esse fenômeno não estava ocorrendo em igual proporção [grifos nossos]. Além disso, constatava-se que o curso de graduação em Ciências Contábeis mantinha uma boa demanda de alunos e um número expressivo de vagas em faculdades de todo o Brasil, o que não ocorria com os cursos de pós-graduação stricto sensu da área. (Santos \& Girotto, 2006, p. 18).

Já a virada positivista, que à primeira vista pode indicar uma ruptura com a tradição prévia do campo, parece ter decorrido não de estratégias de subversão por parte de postulantes ao acesso, mas, sim, de estratégias de conservação levadas a cabo por agentes em posições dominantes. Mudanças implementadas pela Capes no sistema de avaliação da pós-graduação brasileira implicaram o descredenciamento de dois programas de pós-graduação em contabilidade em 2004 (Peleias et al., 2007) este cenário de pressão externa, a ascensão do positivismo cumpriu o papel de "cientificizar" os discursos do campo, permitindo o acesso de seus produtos a canais de divulgação já estabelecidos em outras disciplinas e a emulação desses canais nos periódicos da própria área, contribuindo para preservá-la.

Porém, a leitura de Dias Filho e Machado (2004) e sua lista de referências testemunha que à época dessa virada já se tinha contato com textos das diferentes vertentes que encontram espaço na literatura contábil internacional. Se tal virada representasse, de fato, um processo de autonomização do campo científico, seria esperado que também a literatura nacional fosse marcada pela diversidade de abordagens a partir de então. O que se viu, contudo, foi um predomínio quase absoluto do positivismo, que, com sua reificação do status quo, sob a alegação de objetividade, permitiu que a academia contábil brasileira continuasse, agora sob a forma de coeficientes e níveis de significância, a reafirmar interesses do campo profissional: infindáveis estudos de value relevance com o objetivo de "provar" a importância da informação contábil; problemas de pesquisa que tomam apenas "o investidor" e "o gestor", ou quando muito "o credor", como parâmetro de interesses; e insistência em temas ligados ao mercado de capitais, com o qual o segmento acadêmico sempre manteve vínculos estreitos, a despeito de sua pouca relevância como fonte de financiamento e alternativa de investimento na economia brasileira.

Em minha vivência, nos últimos anos, como discente de um programa de pós-graduação em Contabilidade, tenho percebido a emergência de um conjunto de postulantes que aparenta adotar estratégias de ruptura em busca de maior prestígio no campo acadêmico. Tal conjunto é composto, majoritariamente, por indivíduos cujas carreiras são construídas essencialmente por meio do próprio campo acadêmico, pela ocupação de postos na burocracia universitária, em contraposição àqueles com maior vivência no campo profissional. Porém, parece haver um acordo tácito entre as frações em disputa, pelo qual os heréticos limitam-se a temas correlatos, como história, educação ou relações de gênero e raça, buscando mobilizar na área um capital cultural acumulado a partir de outras disciplinas, enquanto os ortodoxos mantêm controle estreito sobre temas mais caros à profissão, como regulação e práticas contábeis, de modo que a Contabilidade em si não seja objeto de questionamentos. 
Em face desse cenário, as perspectivas de que tais movimentações contribuam para uma maior autonomização do campo científico em relação ao campo profissional não me parecem promissoras. $\mathrm{O}$ segmento ortodoxo detém maior capacidade de cooptação da clientela discente, pois controla uma maior oferta de ganhos externos ao campo científico, e ensaia, inclusive, um retorno ao normativismo. Tal clientela também se divide em alguns segmentos: profissionais experientes que buscam capital cultural para retornar ao mercado de trabalho em melhor posição; professores vinculados a universidades públicas, que visam a progressão de carreira; e egressos recentes da graduação que ainda buscam se inserir no mercado de trabalho, mas não necessariamente no meio acadêmico. Em comum, quase todos compartilham a visão da pesquisa como um meio para atingir outras finalidades, implicando na falta de ambição intelectual que motive os investimentos em preparo científico necessários para promover mudanças substanciais no campo.

\section{Considerações Finais}

Para melhor compreender a ausência de uma linha consolidada de pesquisas interpretativas e críticas em Contabilidade no Brasil, analisei ao longo deste artigo a constituição do campo científico na área, valendo-me da literatura acadêmica, de fontes documentais e de minha própria trajetória nesse campo como fontes de evidências, e empregando um referencial sociológico para interpretar a baixa diversidade da produção científica da área, apontada por estudos que se limitam a indicadores bibliométricos ou a aspectos epistemológicos.

Ao adotar uma lógica abdutiva, apresentei a hipótese de que a pouca diversidade observada na pesquisa contábil feita no Brasil é consequência da baixa autonomia do campo científico em relação ao campo profissional: a organização da profissão precedeu o estabelecimento dos cursos superiores em Contabilidade, cujas origens remontam a esforços levados a cabo por lideranças do campo profissional; as posições de destaque no meio acadêmico, ao longo dos anos, foram ocupadas por indivíduos com atuação destacada também no campo profissional; e entidades representativas da profissão, notadamente o CFC, ainda hoje conduzem diversas iniciativas visando pautar o ensino de Contabilidade, encontrando amplo apoio no próprio meio acadêmico. A prevalência da abordagem positivista, por sua vez, também pode ser interpretada à luz dessa falta de autonomia, pois a reificação do status quo que lhe é característica permite a reprodução, sob uma aura de cientificidade, dos discursos oriundos do campo profissional.

Na literatura internacional, além das influências da profissão contábil (Gendron \& Bédard, 2001; Sikka et al., 1995), já foram apontados como motivos para a falta de diversidade no mainstream da pesquisa em Contabilidade o poder exercido pelos corpos editoriais dos periódicos de maior destaque (Baker \& Bettner, 1997), o atrelamento da progressão na carreira acadêmica a publicações em tais periódicos (Hopwood, 2007; Humphrey \& Gendron, 2015; Merchant, 2010), o aumento da autonomia, e, consequente, isolamento do campo acadêmico em relação à prática contábil (Hopwood, 2007; Jeanjean \& Ramirez, 2009), a redução do financiamento à pesquisa, a introdução de critérios de alocação de recursos por meio de indicadores de desempenho acadêmico baseados em rankings de periódicos, e uma busca por "internacionalização" que leva à emulação de modos de pensar e conduzir pesquisas tipicamente anglo-saxões (Humphrey \& Gendron, 2015).

Mas, no contexto brasileiro, ainda que esses demais fatores possam ajudar a compreender como se dá a reprodução do paradigma prevalente, entendo que eles não são exclusivos da área Contábil, afetando também disciplinas correlatas nas quais existe uma diversidade maior. Assim, a interpretação de que a pouca diversidade da pesquisa contábil brasileira decorre de uma baixa autonomia em relação ao campo profissional é reforçada pelas comparações à área de Administração, na qual há uma comunidade de pesquisadores críticos estabelecida desde os anos 1970: em que pese a afinidade temática com a Contabilidade, a origem do campo acadêmico precedeu a organização da profissão de Administrador, conferindo-lhe uma maior autonomia que se reflete em uma também maior diversidade paradigmática. 
Como em toda análise que abranja tão longo período histórico em tão curta narrativa, não pude dar conta de toda a diversidade que caracterizou a constituição do campo científico na Contabilidade brasileira, tendo necessitado recorrer a generalizações que possivelmente não façam justiça a todos os atores envolvidos nesse processo. O desenvolvimento de áreas específicas da disciplina, como a Contabilidade Gerencial, e a influência dos cenários acadêmicos internacionais, por exemplo, são aspectos que podem ser mais bem explorados em pesquisas futuras. A identificação da falta de autonomia em relação aos interesses da profissão como o maior empecilho para a ampliação da variedade temática, metodológica e epistemológica da pesquisa contábil feita no Brasil, por sua vez, contribui como um alerta para os efeitos deletérios que podem advir dos constantes apelos por uma maior aproximação entre a academia e a prática contábil, se tal aproximação se der sob as atuais condições de subordinação do campo científico a interesses do campo profissional.

\section{Referências}

Agrizzi, D., \& Sian, S. (2015). Artificial corporatism: a portal to power for accountants in Brazil. Critical Perspectives on Accounting, 27, pp. 56-72. DOI: https://doi.org/10.1016/j.cpa.2014.02.003

Alcadipani, R. (2005). Réplica: a singularização do plural. Revista de Administração Contemporânea, 9(1), pp. 211-220. DOI: https://doi.org/10.1590/S1415-65552005000100011

Arduini, D., Oliveira, F. de, \& Rodrigues, T. (2015). Belo Horizonte recebe coordenadores e professores de Ciências Contábeis do País. Jornal do CFC, 18(130), pp. 17-20.

Baker, C. R., \& Bettner, M. S. (1997). Interpretive and critical research in accounting: a commentary on its absence from mainstream accounting research. Critical Perspectives on Accounting, 8(4), pp. $293-$ 310. DOI: https://doi.org/10.1006/cpac.1996.0116

Barbosa, A. G. (2003). "Quem sabe faz, quem não sabe ensina." Jornal do CFC, 6(63), p. 2.

Barbosa, M. A. C., Santos, J. M. L., Matos, F. R. N., \& Almeida, A. M. B. (2013). Nem só de debates epistemológicos vive o pesquisador em administração: alguns apontamentos sobre disputas entre paradigmas e campo científico. Cadernos EBAPE.BR, 11(4), pp. 636-651.

Bertero, C. O., Caldas, M. P., \& Wood Jr., T. (1999). Produção científica em administração de empresas: provocações, insinuações e contribuições para um debate local. Revista de Administração Contemporânea, 3(1), pp. 147-178. DOI: https://doi.org/10.1590/S1415-65551999000100009

Borges, E. F., Rodrigues, J. M., Silva, C. A. T., \& Santana, C. M. (2011). Paradigmas na pesquisa contábil no Brasil: um estudo epistemológico sobre a evolução nos trabalhos de programas de pós-graduação em ciências contábeis. ConTexto, 11(19), pp. 21-30. DOI: https://doi.org/10.1073/pnas.0703993104

Bourdieu, P. (1976). Le champ scientifique. Actes de la Recherche en Sciences Sociales, 2, pp. 88-104. DOI: https://doi.org/10.3406/arss.1976.3454

Bourdieu, P. (1980). Le Sens Pratique. Paris: Les Editions de Minuit.

Bourdieu, P. (1989). O Poder Simbólico. (F. Tomaz, Trad.). Rio de Janeiro: Bertrand Brasil.

Bourdieu, P. (2002). The forms of capital. In N. W. Biggart (Ed.), Readings in Economic Sociology (pp. 280291). Malden: Blackwell.

Bourdieu, P., \& Wacquant, L. J. D. (1992). An Invitation to Reflexive Sociology. Chicago: University of Chicago Press.

Cardoso, R. L., Mendonça Neto, O. R., Riccio, E. L., \& Sakata, M. C. G. (2003). Pesquisa científica em contabilidade entre 1990 e 2003. Revista de Administração de Empresas, 45(2), pp. 34-45. 
Cardoso, R. L., Oyadomari, J. C. T., \& Mendonça Neto, O. R. (2007). Influências da positive accounting nos programas de mestrado em contabilidade: uma análise bibliométrica da produção acadêmica de 2002 a 2005. Brazilian Business Review, 4(2), pp. 158-170.

Castro, C. M. (1981). O ensino da administração e seus dilemas: notas para debate. Revista de Administração de Empresas, 21(3), pp. 58-61. DOI: https://doi.org/10.1590/S0034-75901981000300006

Dias Filho, J. M., \& Machado, L. H. B. (2004). Abordagens da pesquisa em contabilidade. In S. Iudícibus \& A. B. Lopes (Coords.), Teoria Avançada da Contabilidade (pp. 15-69). São Paulo: Atlas.

Faria, A. (2005). Réplica: ampliando questionamentos sobre crítica em administração. Revista de Administração Contemporânea,9(1), pp. 221-236. DOI: https://doi.org/10.1590/S1415-65552005000100012

Gendron, Y., \& Bédard, J. (2001). Academic auditing research: an exploratory investigation into its usefulness. Critical Perspectives on Accounting, 12(3), pp. 339-368. DOI: https://doi.org/10.1006/ cpac.2000.0429

Girotto, M. (2010). Inscrições abertas para o primeiro Exame de Suficiência de 2011. Jornal do CFC, 13(106), p. 3.

Glynos, J., \& Howarth, D. (2007). Logics of Critical Explanation in Social and Political Theory. London: Routledge.

Hopwood, A. (2007). Whither accounting research? The Accounting Review, 82(5), pp. 1365-1374. DOI: https://doi.org/10.2308/accr.2007.82.5.1365

Humphrey, C., \& Gendron, Y. (2015). What is going on? The sustainability of accounting academia. Critical Perspectives on Accounting, 26, pp. 47-66. DOI: https://doi.org/10.1016/j.cpa.2014.09.008

Jeanjean, T., \& Ramirez, C. (2009). Back to the origins of positive theories: a contribution to an analysis of paradigm changes in accounting research. Accounting in Europe, 6(1), pp. 107-126. DOI: https:// doi.org/10.1080/17449480902896510

Leite Filho, G. A. (2008). Padrões de produtividade de autores em periódicos e congressos na área de contabilidade no Brasil: um estudo bibliométrico. Revista de Administração Contemporânea, 12(2), pp. 533-554. DOI: https://doi.org/10.1590/S1415-65552008000200011

Lima, L. A. (2011). A representação das múltiplas dimensões paradigmáticas no estudo da administração: um ensaio sobre os limites contidos nas defesas paradigmáticas excludentes. Revista de Administração Contemporânea, 15(2), pp. 198-208. DOI: https://doi.org/10.1590/S1415-65552011000200003

Mendonça Neto, O. R., Cardoso, R., \& Oyadomari, J. C. (2012). A profissionalização do contador no Brasil. BASE - Revista de Administração e Contabilidade da Unisinos, 9(4), pp. 393-406. DOI: https:// doi.org/10.4013/base.2012.94.06

Mendonça Neto, O. R., Riccio, E. L., \& Sakata, M. C. G. (2009). Dez anos de pesquisa contábil no Brasil: análise dos trabalhos apresentados nos ENANPADs de 1996 a 2005. Revista de Administração de Empresas, 49(1), pp. 62-73. DOI: https://doi.org/10.1590/S0034-75902009000100008

Merchant, K. A. (2010). Paradigms in accounting research: a view from North America. Management Accounting Research, 21(2), pp. 116-120. DOI: https://doi.org/10.1016/j.mar.2010.02.004

Misoczky, M. C. (2006). Sobre o centro, a crítica e a busca da liberdade na práxis acadêmica. Cadernos EBAPE.BR, 4(3), pp. 1-13. DOI: https://doi.org/10.1590/S1679-39512006000300002

Misoczky, M. C., \& Amantino-de-Andrade, J. (2005a). Tréplica: quem tem medo do fazer acadêmico enquanto práxis? Revista de Administração Contemporânea, 9, pp. 237-243. DOI: https://doi. org/10.1590/S1415-65552005000100013 
Misoczky, M. C., \& Amantino-de-Andrade, J. (2005b). Uma crítica à crítica domesticada nos estudos organizacionais. Revista de Administração Contemporânea, 9(1), pp. 192-210. DOI: https://doi. org/10.1590/S1415-65552005000100010

Nascimento, A. R. do, Junqueira, E., \& Martins, G. de A. (2010). Pesquisa acadêmica em contabilidade gerencial no Brasil: análise e reflexões sobre teorias, metodologias e paradigmas. Revista de Administração Contemporânea, 14(6), pp. 1113-1133. DOI: https://doi.org/10.1590/S141565552010000700008

Nicolini, A. (2003). Qual será o futuro das fábricas de administradores? RAE. Revista de Administração de Empresas, 44(2), pp. 44-54.

Passos, W. (2004). Exame de Suficiência se consolida perante a sociedade, mas índice de reprovação preocupa especialistas. Revista Brasileira de Contabilidade, 33(146), pp.14-21.

Peleias, I. R., \& Bacci, J. (2004). Pequena cronologia do desenvolvimento contábil no Brasil: os primeiros pensadores, a padronização contábil e os congressos brasileiros de contabilidade. Revista Administação On Line - FECAP, 5(3), pp. 39-54.

Peleias, I. R., Silva, G. P., Segreti, J. B., \& Chiorotto, A. R. (2007). Evolução do ensino da contabilidade no Brasil: uma análise histórica. Revista Contabilidade \& Finanças, 18(spe), pp. 19-32. DOI: https:// doi.org/10.1590/S1519-70772007000300003

Ribeiro, S. L. S. (Org.). (2009). Contando história: o Departamento de Contabilidade e Atuária - FEA/USP entre números e palavras. São Paulo: D’Escrever.

Rodrigues, L. L., Schmidt, P., \& Santos, J. L. (2012). The origins of modern accounting in Brazil: influences leading to the adoption of IFRS. Research in Accounting Regulation, 24(1), pp. 15-24. DOI: https:// doi.org/10.1016/j.racreg.2011.12.003

Rodrigues, L. L., Schmidt, P., Santos, J. L., \& Fonseca, P. C. D. (2011). A research note on accounting in Brazil in the context of political, economic and social transformations, 1860-1964. Accounting History, 16(1), pp. 111-123. DOI: https://doi.org/10.1177/1032373210373799

Rosa, A. R., \& Alcadipani, R. (2013). A terceira margem do rio dos estudos críticos sobre administração e organizações no Brasil: (re)pensando a crítica a partir do pós-colonialismo. RAM. Revista de Administração Mackenzie, 14(6), pp. 185-215. DOI: https://doi.org/10.1590/S1678-69712013000600009

Santos, F. (Ed.). (2008a). CFC lança proposta nacional de conteúdo para o curso de graduação em ciências contábeis. Jornal do CFC, 11(94), p. 7.

Santos, F. (Ed.). (2008b). CFC realiza curso de contabilidade internacional. Jornal do CFC, 11(93), pp. 4-5.

Santos, F. \& Girotto, M. (2006). Conheça o Programa Excelência na Contabilidade. Revista Brasileira de Contabilidade, 35(159), pp. 16-27.

Sikka, P., Willmott, H., \& Puxty, T. (1995). The mountains are still there: Accounting academics and the bearings of intellectuals. Accounting, Auditing \& Accountability Journal, 8(3), pp. 113-140. DOI: https://doi.org/10.1108/09513579510094723

Theóphilo, C. R., \& Iudícibus, S. (2005). Uma análise crítico-epistemológica da produção científica em contabilidade no Brasil. Contabilidade, Gestão e Governança, 8(2), pp. 147-175.

Wacquant, L. (2013). Symbolic power and group-making: on Bourdieu's reframing of class. Journal of Classical Sociology, 13(2), pp. 1-18. DOI: https://doi.org/10.1177/1468795X12468737 